\title{
ATUALIDADE DA REIFICAÇ̃̃O DE MARX COMO INSTRUMENTO DA ANÁLISE DE RELAÇÕES JURÍDICAS E SOCIAIS
}

\author{
Martonio Mont'Alverne Barreto Lima ${ }^{a}$
}

a Professor titular em Direito da Universidade de Fortaleza (Unifor).Fortaleza, Brasil. barreto@unifor.br

Orcid: 0000-0003-0052-2901

\section{Walquíria Gertrudes Domingues Leão Rego ${ }^{\mathrm{b}}$}

'Professora titular em Ciências Sociais da Universidade Estadual de Campinas (Unicamp). Campinas,

Brasil.w.leaorego@uol.com.br

Orcid: 0000-0002-8356-2097

http://dx.doi.org/10.1590/0102-193228/109

Mas se os trabalhadores pudessem viver do ar, não poderiam ser comprados por qualquer preço. Sua gratuidade é, portanto, um limite no sentido matemático, sempre inatingível, embora sempre

aproximável. É a tendência constante do capital rebaixar os trabalhadores até este ponto niilista. Um escritor do século XVIII, frequentemente citado por mim, o autor do "Essay on Trade and Commerce", apenas trai o segredo espiritual mais intimo do capital inglês, ao esclarecer que a tarefa histórica da Inglaterra na vida é rebaixar o salário inglês para o nível do francês e do holandês. MARx, ERSTER BAND

\section{Introdução}

Este artigo objetiva uma revisitação temática sobre a categoria da reificação como fenômeno social, percorrendo passagens das obras de Marx: $O$ Capital e Grundrisse.

\footnotetext{
1 Do original: "Wenn aber die Arbeiter von der Luft leben könnten, so wären sie auch um keinen Preis zu kaufen. Ihr Nichtkosten ist also eine Grenze im mathematischen Sinn, stets unerrereichbar, obgleich stets anäherbar. Es ist die beständige Tendenz des Kapitals, sie auf diese nihilistischen Standpunk herabzudrücken. Ein oft von mir zitierter Schriftsteller des 18. Jahrhundert, der Vaerfasser des, Essay on Trade and Commerce”, verräter nur das inneste Seelengeheimnis des englischen Kapitals, wenn er für die historische Lebensaufgabe Englands erklärt, dn englischen Arbeitslohn auf das französische und holländische Niveau herbazudrücken".
} 
A proposta de realizar tal empreendimento se liga ao fato de que estamos conscientes da dificuldade da tarefa, pois se trata de uma tentativa de reinserir o assunto no atual debate sociológico-jurídico, o qual se desenvolve em muitos lugares do mundo. Consideramos, então, o conceito de reificação como um conceito-diagnóstico, ou pelo menos um elemento indispensável de diagnose de uma época histórica. Isto se deve, na verdade, ao fato de tal debate tratar de um fenômeno ligado às formas de consciência e dos conjuntos de práticas sociais inspirados nela, e que podem singularizar um determinado tempo histórico. Semelhante campo temático foi abandonado por anos, ao menos desde os anos de 1980, pelas ciências sociais e jurídicas. Contudo, deve ser dito que tal temática foi central nos debates na Alemanha, na Áustria e na América Latina nas décadas de 1920 e 1930, perdurando, após a Segunda Guerra Mundial, até a década de 1980. Sendo assim, tal silenciamento pelos anos 1990 e o 194 começo do século XXI ainda precisa ser explicado.

Entretanto, não cabe nos limites deste artigo tentar sua explicação, uma vez que precisaríamos investigar as razões políticas e teóricas para diagnosticar as causas profundas de semelhante silêncio. De qualquer maneira - e felizmente -, o tema que estamos discutindo foi retomado no debate sociológico internacional, em alto nível, por Axel Honneth (2007), entre outros autores importantes, tais como Rahel Jaeggi (2017) e Remo Bodei (2004) em reconhecidas obras. Os autores fazem outro percurso para discutir e analisar a temática em questão, utilizando-se de vasta pesquisa bibliográfica contemporânea, tais como as teorias normativas da ação social, a psicanálise, a teoria política. Apropriam-se bastante da potência normativa de certo liberalismo, especialmente, o de inspiração kantiana, com destaque para os autores que trabalham com a temática da autonomia individual, como Joseph Raz (The Morality of Freedom), com especial acento na ideia de autoria da própria vida, por parte 
dos indivíduos. Apenas consideramos nosso dever esclarecer que, no texto que ora apresentamos, quisemos revisitar Marx e a principal formulação neste campo realizada em 1923 por Georg Lukács (2003), obra seminal que fertilizou e fertiliza o debate sobre a relação entre consciência e sociedade. ${ }^{2}$

Desta forma, o texto procurará discutir o conceito de reificação em Marx não somente relacionado com o modelo econômico de produção, caracterizador de sua teoria da história, embora não imobilizador desta consolidada tentativa teórica (Cohen, 2013; Shaw, 1978). Se por um lado o ponto de partida marxiano para a reificação destaca a condição econômica, por outro, os estudos marxianos deixam amplo espaço para a compreensão da reificação no âmbito de outras relações sociais, o que inclui aquelas legais decorrentes da prática e da aplicação concretas do Direito aos casos em disputas entre as distintas classes sociais.

O esforço aqui empreendido não consistirá na busca de encontrar em Marx uma teoria do Direito, pois se entregar a tal propósito seria inútil: não há uma teoria do Direito em Marx. Porém, o desafio parece ser mais instigante, isto é, o de procurar o que pode ganhar a teoria do Direito com Marx e suas reflexões, especialmente o Direito Constitucional, que nada mais é do que Direito Político.

O tema da reificação, de muitas maneiras, está posto na história do pensamento ocidental desde os gregos. Para tanto, pode-se invocar como representativo da preocupação com o problema a alegoria da caverna, de Platão. Ali, está exposto o jogo de luz e sombras existente na percepção dos sujeitos sobre os objetos do mundo.

\footnotetext{
2 Embora deva ser destacado que Axel Honneth é reconhecido por seus vínculos intelectuais e profissionais com a Escola de Frankfurt, especialmente a partir de 1996, quando ingressou na Universidade de Frankfurt e dirigiu de 2001 a 2018 o conhecido Instituto de Pesquisa Social (Institut für Sozialforschung), berço desta Escola. Honneth desenvolveu uma de suas principais obras: Kampf um Anerkennung: zur moralischen Grammatik sozialer Konflikte, cujo conceito de reconhecimento parte de Hegel.
} 
Segundo Leo Strauss, o acontecimento filosófico fundamental nesta perspectiva se refere ao fato pelo qual os gregos conseguiram problematizar a questão da natureza, e, por conseguinte, diferenciando o mundo da natureza e o da convenção, do artefato humano, ou seja, o das criações humanas, das fundações institucionais, políticas e sociais. Deste modo, é que Strauss chama atenção para a definição de Aristóteles: os filósofos são os homens que discutem sobre a natureza, distintos dos homens que discutem sobre os deuses. "a filosofia, diferentemente do mito, começou a existir quando a natureza foi descoberta, ou o primeiro filósofo foi o primeiro homem que descobriu a natureza" (Strauss, 2014, p. 134, tradução nossa). É necessário, neste sentido, que se recupere tal aspecto sem cair na fácil tentação de que se pode medir o passo com o metro do presente. O auxílio da perspectiva grega empresta-nos o exemplo de que relações com a natureza, com sua utilização e constante 196 busca de sua submissão aos interesses humanos, são complexas, e nem sempre os homens conseguem dominar a natureza como desejam. A atribuição das tarefas dos deuses para fenômenos naturais cuja explicação científica ainda era impossível constitui-se apenas num dos mais significativos elementos da cultura ocidental, isto é, no "maravilhoso", ainda presente de forma lapidar no clássico épico da modernidade, Os Lusíadas, cuja lembrança do Gigante Adamastor é somente uma das mais significativas ${ }^{3}$ - eis apenas uma das razões do interesse em recordar o referido ponto.

A lembrança traz à tona outro acontecimento: o da procura da verdade em se constituir como força condutora do ato de pensar; não basta mais narrar a tradição mitológica repetidamente rememorada: a verdade deve ser investigada. Aos sofistas e sua força na retórica argumentativa,

\footnotetext{
3 "Tão grande era de membros que bem posso/Certificar-te que este era o segundo/De Rhodes estranhíssimo Colosso" (Camões, 2014, p. 134).
} 
sobrevieram os filósofos que buscavam a verdade, não se intimidando nem por sua eventual impossibilidade, como alardeada pelos sofistas, tampouco se curvando ao costume fácil pela obviedade da aparência, ou seja, da verdade. Emergiu deste mesmo movimento, como princípio diretivo da busca desta verdade, a desconfiança perene do pensamento, do mundo das aparências, das formas pelas quais os fenômenos se apresentam no mundo. Isto é, das ilusões formais que se produzem na superfície da sociedade.

Desta forma, o conceito marxiano de reificação possui suas raízes na recuperação do acúmulo deste passado cultural para a explicação encontrada no capítulo 48 do Livro III de $O$ Capital. Neste momento, devidamente percebido e dissecado por Lukács (2003, p. 212s), a reificação Verdinglichung - se deixa traduzir nas formas adquiridas pela propriedade, pelas ações e relações humanas; formas agora independentes e que sujeitam a si os homens que a criaram, por meio do capital e de seu movimento. Como consequência, a reificação consistirá num caso "especial de alienação, sua forma mais radical e generalizada, característica da moderna sociedade capitalista" (Bottomore, 1983, p. 314). Nas conhecidas palavras de Marx:

No capital-lucro, ou melhor capital-juros, terra-renda fundiária, trabalho-salários, nesta Trindade econômica como conexão dos componentes de valor e riqueza além e acima de suas fontes, completam a mistificação do modo de produção capitalista, a reificação das relações sociais, a incomensurável junção das relações de produção material com sua determinação histórico-social: o mundo encantado, invertido e posto de cabeça para baixo, onde Monsieur le Capital e Madame la Terre assombram como fantasmas, ora 
como personagens sociais e ao mesmo tempo como meras coisas. (Marx, 1969b, p. 838, tradução nossa) ${ }^{4}$

O ponto de partida do texto será esta percepção marxiana, na tentativa de compreensão do fenômeno jurídico, limitada ao constitucional. A tradicional divisão entre Direito Público e Privado remete a categorias próprias, as quais se encontram em uma "metódica jurídica" - e não simplesmente em um "método" jurídico - explicação satisfatória para a compreensão estruturante do Direito, com respeito às peculiaridades de suas formas de desenvolvimento. Em outras palavras, há requisitos de percepção para que seja claro o elo entre o Direito e a tensão política, não apenas como uma simples reprodução. A metódica jurídica possui, assim, a tarefa de esclarecer as outras funções da realização do Direito "(legislação, governo, administração, jurisprudência, ciência)", sem ignorar a ação de outras "possibilidades de controle (políticas, sociais, públicas, não públicas, informais)" sobre o Direito (Müller e Christensen, 2002, p. 27).$^{5}$

As relações acima identificadas por Marx entre capital, renda, terra e salários receberam modernização que não se pode cobrar de Marx: impossível exigir de um pensador realidade inexistente à sua época. Por outro lado, a "metódica" de compreensão de como esta complexidade modernizou-se e sua essência, não assombrada pela aparência, parece ser possível e se se reconhece a dialeticidade de tal processo de mudança.

\footnotetext{
${ }^{4}$ Do original: "Im Kapital-Profit, oder noch besser Kapital-Zins, Boden-Grundrente, ArbeitArbeitslohn, in diese ökonomischer Trinität als dem Zusammenhang der Bestandteile des Werts und des Reichtums überhaput mit seinen Quellen ist die Mystification der kapitalistischen Produktionsweise, die Verdinglichung der gesellschfatlichen Verhältnisse, das unmitlebare Zusammenwachsen der stofflichen Produktionverhältnisse mit ihrer geschichtlich-sozialer Bestimmheit vollendet: die verzauberte, verkehrte und auf den Kopf gestellt Welt, wo Monsieur le Capital und Madame la Terre als soziale Charaktere und zugleich unmitelbar als bloße Dinge ihren Spuk treiben”.

5 Do original: “(Gesetzgebung, Regierung Verwaltung, Rechstsprechung, Wissenschaft) [...] (politische, soziale, öffentliche, nicht-öffentliche, informelle) Kontrollmöglichkeiten”.
} 
O objetivo do texto é enriquecer, portanto, a análise do Direito com a inspiração marxiana. A pesquisa é bibliográfica, de busca nas fontes marxianas primárias, especialmente aquelas publicadas no Marx-Engels-Werke (MEW). A tradução das fontes utilizadas desta conhecida coleção é de inteira responsabilidade dos autores.

No primeiro momento do texto, julgamos necessária a abordagem do ambiente cultural europeu que assiste ao nascimento do capitalismo como forma de organização do Estado e da sociedade, uma vez que tradição cultural alimentará não somente as estruturas do desenvolvimento do capitalismo, como será ela objeto das transformações. Uma vez compreendido e preparado o ambiente cultural, segue-se a incursão sobre o conceito de reificação nas relações jurídicas e como estas também se constituem em manifestações do Estado capitalista. Tais relações jurídicas reificadas alcançam a consciência política, o que consiste no terceiro instante deste artigo, a procurar compreender este processo. As conclusões apontam a síntese de nossa visão sobre o conjunto aqui brevemente descrito.

\section{Renascença e ilustração}

A humanização da natureza pelo trabalho dos homens, por sua atividade racional que a modela, criando civilização e cultura, no sentido que lhe conferiu Jacob Christoph Buckhardt, no seu clássico sobre A Cultura do Renascimento na Itália (1990), imporá aos homens sua visão de mundo, sua Weltanschauung. Os homens constituem-se como demiurgos do mundo, pois, no ato de transformação da natureza, transformam-na em civilização; nesta perspectiva, torna-se sujeito, porque pode modificar o mundo, agindo na história e transformando, assim, a natureza e a própria história, conferindo-lhe sentidos e significados, afinal, o que seria o agir no mundo?

Quais sentidos servirão como fundamentos do modo de produção capitalista, com os requisitos que lhe são inerentes, 
e quais laços e experiências precisam ser dissolvidos para o capitalismo se reproduzir? Não se trata, portanto, da construção de sentidos e significados distantes da construção e preservação da ordem econômica capitalista, apesar de comportar divergências aqui e acolá, o que exige maior esforço para a compreensão de sua múltipla natureza. No âmago desta referida multiplicidade encontra-se, também, o Direito, e, não raro, sob a forma de Estado de Direito, o que não destitui a condição de reificação capitalista em suas relações intrínsecas. Em outras palavras, o que se diz ser Estado de Direito, nada mais corresponderia ao "retrato" da luta de classes pela apropriação dos meios de produção, transformado pelo liberalismo em Estado de Direito, como se este de todos fosse, como se a todos assegurasse indistintamente os pilares do mesmo liberalismo: igualdade, liberdade de expressão e de associação, liberdade de ir e vir, propriedade privada.

A temática da ação do homem sobre a natureza, decor200 rente de suas atividades econômicas e políticas, desdobra-se sobre outro problema, vale dizer: sobre quais mediações sociais, sobre que quadro societário se desenvolverão as relações entre homem e natureza, e, sobretudo, em que condições suas capacidades humanas são aproveitadas por eles mesmos, tornando-os, de fato, senhores de si, de seu corpo, de sua alma, de sua subjetividade, e, ao mesmo tempo, fazendo com que sejam objetos desta imanência.

As perguntas que brotam neste âmbito são numerosas. Selecionaremos uma das fundamentais: aquela que diz respeito à natureza dos fenômenos históricos, os modos como se constituem e se apresentam diante da consciência. Portanto, será posto para o pensamento o seguinte desafio: como explicar, como compreender e distinguir, neste processo, as relações entre essência e aparência da realidade dos fenômenos políticos que foram juridicizados, ou seja, que foram constitucionalizados para que se recorra ao sentido da modernidade consagrado após a Revolução Francesa de 1789? 
Semelhantes perguntas apareceram de muitas maneiras ao longo da história do pensamento. A forte intuição filosófica que percebia que os mitos - as magias, os fantasmas, os ritos sacrificiais, os deuses, o mundo encantado dos demônios, das superstições, dos ordálios como forma de prova jurídica - constituíam, fundamentalmente, um mundo encantado que, criado pelos homens, tornava-se fonte de escravidão de seus corpos e almas. Esta transfiguração alimentou a cultura grega desde o conhecido diálogo socrático sofista, registrado por Platão: "Sócrates [...] Tomam as formas de políticos, ou de sofistas, e outras vezes dariam ainda, para certas pessoas, a impressão de estarem completamente em delírio [...]. Teodoro - A quem? Sócrates - Ao sofista, ao político e ao filósofo" (Platão, 1991, p. 206).

O caráter transcendente dos gregos não servia de fundamento final para a compreensão da política, do Estado e das ações, uma vez que esta antiguidade procurou a razão para guiar as ações humanas e, nesta mesma razão, a natureza explicativa dos acontecimentos sociais. A transcendência como dado determinante das ações humanas, e para a formulação das formas jurídicas de Estado, é que persistiu nas formas de explicação das aparências pela modernidade, até que se apoderou da razão humana completamente sob a forma teológica. A emancipação do pensamento desta teologia encontrou em Spinoza decidida concepção: "quem faz da razão e da filosofia servas da teologia, ensandecerá" (Espinoza, 2003, p. 224) ${ }^{6}$ Deste ponto em diante, o duelo se estenderá até os dias atuais, com o registro de que, dificilmente, a transcendência manteve sua hegemonia cultural após os séculos XVIII e XIX, no que pesem as tentativas, com destaque para aquela que se desenvolveu na segunda década do século XXI, travestida de histeria obscurantista chamada de neoliberalismo e no campo religioso de pentecostalismo, tão presente nas Américas.

${ }^{6}$ Do original: "hic scilicet sine ratione, ille vero cum ratione insaniet" (Spinoza, 2008, p. 444). 
O Iluminismo se apresentou e se opôs à religião, à concepção do mundo e aos atos humanos como produto da fé. Tratou-se de um "programa de desencantamento do mundo. Seu objetivo era a dissolução dos mitos e a queda da imaginação através do saber”. Assim, consistia este programa no oferecimento de novos sentidos à história; novos sentidos que, até então, haviam sido impedidos pelos adeptos da tradição, pela aversão à dúvida, pelo fetichismo verbal responsáveis pela inexistência de um "casamento feliz da compreensão humana com a natureza das coisas" (Horkheimer e Adorno, 1997, p. 19, tradução nossa). ${ }^{7}$

Se este foi o objetivo do Iluminismo, mais tarde Horkheimer (1976, p. 17) reconhecerá que a mesma tão buscada razão, na verdade, "jamais dirigiu verdadeiramente a realidade social, mas hoje está tão completamente expurgada de quaisquer tendências ou preferências específicas, que renunciou, por fim, até mesmo à tarefa de julgar as 202 ações e o modo de vida do homem".

O triunfo do capitalismo foi saudado por Max Weber como desencantamento do mundo, isto é, como a inauguração de uma era onde a racionalidade estendia progressivamente seu sentido e sua lógica a todo o devir histórico da humanidade. Por seu turno, Marx saúda o capitalismo (nas palavras quase eufóricas do Manifesto Comunista) como um momento especial da história, um período histórico de transformações tão profundas e velozes que revolucionavam, de um modo nunca visto, todas as antigas formas de produção econômica, bem como todas as velhas concepções sobre o mundo em geral, o que inclui o Direito.

Agora se podia falar enfaticamente de uma história universal. Todos os povos nos mais longínquos recantos do planeta seriam arrastados por esta avalanche irresistivel que era

\footnotetext{
7 Do original: "Das Program der Aufklärung war die Entzauberung der Welt. Sie wollte die Mythen auflösen und Einbildung duchr das Wissen stürzen. [...] hat die glücklische Ehe des menschlichen Verstandes mit der Natur der Dinge vehindert".
} 
o mercado mundial capitalista, o que tornaria possível a universalização do mundo burguês, no sentido amplo da palavra. Porém, diferentemente de Max Weber, se o capitalismo para Marx significava, de um lado, um inusitado progresso e a vitória de uma determinada razão - embora nem sempre razoável -, de outro fazia emergir das profundezas da história um reino enfeitiçado e desumano, o que exigia a retomada do fundamento de seu pensamento: o mundo da razão. Afinal, a origem do capital como relação social (e na sua forma de acumulação primitiva) figurará "nos anais da humanidade com traços de sangue e fogo" (Marx, 1969b, p. 743, tradução nossa). ${ }^{8}$

Fazia-se, então, imperativo de a razão mobilizá-la como tarefa irrenunciável à pesquisa e compreensão dos processos específicos de encantamento, agora da modernidade. Neste ponto, impõe-se examinar com cuidado o empreendimento de Marx, iluminista radical que se propõe a uma tarefa gigantesca, ou seja, compreender radicalmente a modernidade, desvendar seus principais mistérios, enfim, cumprir radicalmente o programa iluminista. Para tanto, pesquisou os fundamentos da modernidade e suas principais promessas encarnadas nas objetivações mais decisivas realizadas pelos homens. Em outros termos, compreender as razões mais profundas do fato dos homens pagarem o acréscimo de seu poder sobre a natureza, realizado através da ciência, com o estranhamento - agora alienação - diante daquilo que eles mesmos produziram. Por fim, desnudar pela razão metódica quais são os específicos encantamentos constitutivos da modernidade, isto é, do capitalismo, que muito longe de produzir liberdade e igualdade, gerara um tipo de dominação e de servidão muito específico.

Neste sentido, tornava-se forçoso para o sujeito cognoscente atravessar as espessas névoas que envolvem as relações

\footnotetext{
8 Do original: "Und die Geschichte dieser ihrer Expropriation ist in die Analen der Menschenheit eingeschrieben mit Zügen von Blut und Feuer".
} 
sociais, políticas e econômicas e seus modos discursivos dominantes, e, até certo ponto, justificadores das relações determinantes deste tipo novo de sociedade. Neste sentido, o empreendimento investigativo de Marx é, em si mesmo, paradoxal, pois visa jogar luz em meio às luzes do progresso, cantadas em prosa e verso como o conteúdo profundo da forma moderna de convivência cívica. As luzes mais ofuscantes eram, então, as iluminações provindas do liberalismo e de suas brilhantes promessas de igualdade e liberdade através do trabalho e da racionalidade do mercado. Em resumo, a empresa de Marx, de um lado, se empenha em reconhecer o avanço fundamental que este corpo teórico e político significou na história da humanidade e, de outro, pesquisa o fundamento mais recôndito de suas ilusões formais, dos seus modos discursivos de apresentar os fenômenos econômicos e sociais, que será uma tarefa maior.

Trata-se aqui de não somente procurar saber como o 204 capitalista enriqueceu, mas sim de investigar seu poder, seus limites e o caráter desta complexa formação política e social à custa do trabalho da imensa maioria das populações relegadas a miséria e intensa fragilidade de direitos. Trata-se de desvendar como uma inteira estrutura estatal foi sendo transformada a partir da vivência de uma concreta e profunda experiência histórica rumo à satisfação das exigências desta forma de atividade econômica, cuja explicação a respeito da "legislação sanguinária contra os expropriados ao final do século XV" é somente um dos mais valiosos momentos da obra marxiana (Marx, 1968b, p. 761, tradução nossa) ${ }^{9}$

Qual fato decisivo descobre Marx? Identifica suas específicas fantasias, seu encantamento, suas potentes máscaras mais engalanadas, vestindo traje a rigor, mas enfeitiçadoras tanto quanto os antigos ritos sagrados. Os templos e os ritos podem ser outros, mas permanecem enfeitiçando os

9 Do original: “Die Blutgesetzgebung der Expropriierten seite Ende des 15, Jahrhundert". 
homens porque engendram névoas mais espessas na realidade dos fenômenos, a possuírem, de fato, mais potências ocultadoras que agem e coagem os sujeitos. Significa, portanto, compreender as representações de toda uma época, decifrar os saberes, apreender o saber que não é saber e desconstruir analiticamente os modos como os fenômenos sociais se apresentam vestidos na realidade - vestidos agora com os trajes da acumulação, do capital, do dinheiro, dos juros e dos salários. A todos estes personagens, agora mostrados na forma concreta por Marx, acodem as formas jurídicas; em outras palavras: à reificação das relações formadas por "Monsieur le Capital e Madame la Terre", de que nos adverte Marx, corresponde à reificação também das relações jurídicas, mediadas pelo Direito. Não se trata de uma preponderância automática da primeira sobre a segunda forma de reificação mencionada, mas se trata de compreender os complexos nexos entre uma e outra.

Sobre o quê, então, falamos? Referimo-nos a um emaranhado de relações sociais envolvidas em formas de grande poder de convencimento social. Podemos, por exemplo, tomar os pressupostos da troca capitalista nas suas formas jurídicas. Quais são seus pressupostos? Não são desconhecidos: a igualdade, a liberdade dos agentes da troca, a liberdade de circulação de capital. Acompanhemos alguns passos da explicação do autor: nos Grundrisse, Marx explica como se opera a transformação do dinheiro em capital e, para tanto, há uma explicação anterior sobre a natureza do dinheiro, que é comparada ao ouro e à prata. Estes metais não são dinheiro, pois estão na natureza. "Ser dinheiro não é nenhuma propriedade natural do ouro ou da prata [...]. Mas o dinheiro é imediatamente ouro e prata" (Marx, 1983, p. 165, tradução nossa). ${ }^{10}$ Marx sublinha, ainda, o fato de que

${ }^{10}$ Do original: "Geld zu sein ist keine natürliche Eingenschaft des Gold und Silbers [...] Aber Geld ist unmittelbar Gold und Silber". 
ninguém nasce mercadoria, e que a constituição da força de trabalho, seus músculos e nervos não contêm a propriedade "natural" de se converter em mercadoria, em valor de troca, assim como não é inerente ao ouro, na sua condição natural, conter suas propriedades de medida de valor monetário. Por exemplo, no Peru e no México das civilizações pré-colombianas, o ouro servia para ornamentar templos, vestimentas rituais (Marx, 1983), sendo que tais conversões nascem em determinadas formas societárias, ou seja, na sociedade capitalista. Deste modo, são convenções, são artefatos, são criações dos homens e, por esta razão, desnaturam-se. Neste processo de destituição de suas qualidades naturais, reificam-se, transformam-se em bens - ou em coisas - que serão formalizados em complexas relações jurídicas. Onde estaria a chave desta transformação que conduz o homem, o Estado e a sociedade a revolucionarem suas formas de organização para dar espaço às transformações do capitalismo em todas 206 as instâncias de suas vidas? No valor de troca, Tauschwert, nas palavras de Marx (1983, p. 166, tradução nossa, grifo nosso):

assim, a contradição básica contida no valor de troca e no correspondente método de produção da sociedade emerge aqui em toda a sua pureza. As tentativas de abolir esta contradição, privando o dinheiro de sua forma metálica e fazendo dele uma lei externa a uma relação social, cuja última forma seria a do dinheiro do trabalho, já tão criticadas acima. ${ }^{11}$

Residiria no valor de troca um passo histórico na fundamentação da transformação do dinheiro em capital. Trata-se

11 Do original: "Es tritt daher hier in der ganze Reinheit hervor der Grundwiderspruch, der im Tauschwert und der ihm entsprechenden Produktionsweise der Gesellschaft enthalten ist. Die Versuche, diesen Widerspruch aufzuheben, dadurch, daß dem Geld seine metallne Form entzogen und es auch äußerliche als von der Gesellschaft Gesetzes, als Ausdruck eines gesellschaftlichen Verhältnisses gesetz wird, wovon die letzte Form die von Arbeitsgeld wäre, its schon oben kritisiert". 
do capitalismo, da modernidade, onde possuidores de mercadorias diferentes, mas equivalentes, defrontam-se como se fossem "livres compradores e livres vendedores", e se encontram para trocar onde quiserem. É no ato da troca, portanto, que os sujeitos estão postos precisamente como indivíduos, como iguais; é também no ato da troca que os sujeitos se confirmam, ao mesmo tempo, como iguais, contudo, como indiferentes entre si. Será, pois, no âmbito do mercado que se concretiza a relação social e jurídica, na qual aos sujeitos pressupostos como iguais "se agrega a noção de liberdade", como se, de um lado, não estivesse uma histórica situação de miséria que não deixa opção, senão, a venda do próprio corpo - e da consciência em nome da sobrevivência física e, de outro, a acumulação e a circulação do capital.

Aqui, o reconhecimento recíproco da igualdade e da liberdade dos sujeitos constitui a condição natural da troca. Para compreender como se opera a troca entre o capital e o trabalho assalariado, Marx afirma que "o trabalhador troca sua mercadoria, seu trabalho, ou seja, seu valor utilitário, que como qualquer mercadoria também possui um preço, como todos os outros bens, por certa soma de valores, certa soma de dinheiro, que o capital lhe oferece" (Marx, 1983, p. 199 , tradução nossa). ${ }^{12}$

De fato, no mundo da troca, no intercâmbio dos valores de troca, a igualdade dos sujeitos não é uma ilusão, pois afirma-se como necessidade do capitalismo. A astúcia desta ilusão é que Marx procura comprovar que "o interesse universal passa a ser a universalidade dos interesses egoístas" (Marx, 1983, p. 170, tradução nossa). ${ }^{13}$

\footnotetext{
12 Do original: "Der Arbeietr tauscht seine Ware, die Arbeit, den Gebrauchswerte, die als Ware auch eine Preis hat, wie alle andren Waren, aus gegen eine bestimmte Summe Tauschwerte, bestimmte Summe Geld, die das Kapital an ihn ablässt”.

13 Do original: "Das allgemeine Interesse ist eben die Allgemeinheit der selsbtsüchtigen Interessen".
} 
O mesmo se opera com a abstrata confusão entre igualdade e liberdade, como se fossem igualdade e liberdade de todos. Porém, quando se constata o mundo material da realização, tanto individual como coletiva, desta igualdade, coloca-se impositivamente a liberdade. "Desta maneira, igualdade e liberdade não são apenas respeitadas na troca, que se baseia em valores de troca, mas a troca de valores de troca é a base produtiva e real de toda a igualdade e liberdade" (Marx, 1983, p. 170, tradução nossa). ${ }^{14}$

Neste instante, Marx chama a atenção para um ponto importante, qual seja: essas noções de liberdade e igualdade são essencialmente referidas a um período histórico determinado, não sendo universalidades abstratas. Por exemplo: "neste sentido, são igualdade e liberdade exatamente o oposto de liberdade e igualdade antigas, que não possuíram como base o valor cambial desenvolvido, mas foram destruídas pelo seu desenvolvimento" (Marx, 1983, p. 170, tradução nossa).$^{15}$

Assim, postas nestas condições materiais, liberdade e igualdade passam a ser instrumentalizadas na conformidade das relações de troca e do aperfeiçoamento da circulação; se se oferece resistência a uma vontade, o outro lado será forçado a aderir às relações de troca. Sua coercibilidade impregna e se impõe sobre todas as vontades que a constituem: o meu interesse que passa a ser refletido em interesse geral, universal, com poder de obrigar a todos. Marx adverte que mesmo a situação de escravo na antiguidade romana não impediu que, noutros círculos, estranhos à situação do servus, o Direito desenvolvesse as "determinações da pessoa jurídica, exatamente como aquelas do indivíduo na troca,

\footnotetext{
14 Do original: "Gleichheit und Freiheit sind also nicht nur respektiert im Austausch, der auf Tauschwerten beruht, sondern der Austausch von Tauschwerten ist die produktive, reale Basis aller Gleichheit und Freiheit”.

15 Do original: "Gleichheit und Freiheit in dieser Ausdehnung sind grade das Gegenteil der antiken Freiheit und Gleichheit, die eben den entwickelten Tauschwert nicht zur Grundlage haben, vielmehr an seiner Entwicklung kapputgehen".
} 
o que antecipou o Direito da sociedade industrial (em suas determinações fundamentais)" (Marx, 1983, p. 171, tradução nossa).${ }^{16}$ Como se sabe, a pergunta dos antigos versava sempre a respeito do modo de propriedade através do qual seriam criados os melhores cidadãos.

Os indivíduos que intercambiam existem sob determinações diferenciadas do comprador e vendedor: um compra uma mercadoria particular, natural, que é a força de trabalho (músculos, nervos etc.), enquanto o outro vende sua própria pele. A indiferença constitutiva dessa relação está reportada no suposto da equivalência, afinal, o dinheiro (como coisa) circula, ora em umas mãos, ora em outras. Esta indiferença (o dinheiro como equivalente universal) dá materialidade à igualdade e, assim, o dinheiro, então, cumpre a função de nivelador radical, vinculando e abraçando todos os vínculos: "cada qual aparece como o proprietário do dinheiro do outro, até mesmo como dinheiro, se se considera o processo de troca" (Marx, 1983, p. 171, tradução nossa). ${ }^{17}$ A troca é percebida e vivida como ação recíproca dos indivíduos como forma e conteúdo, satisfação interessada de suas necessidades, e, do ponto de vista da forma, como intercâmbio de equivalentes. Enfim, o que sucede com o indivíduo como existência natural de troca? Sua força de trabalho se metamorfoseia em mercadoria; mercadoria que se reivindica produto de uma igualdade resultante de uma liberdade, na qual, na verdade, nem é livre o processo, nem tampouco resultará na igualdade de todos.

A existência do indivíduo enquanto produtor de valor de troca traz a negação absoluta de sua existência natural, tal como nos referimos anteriormente; configura-se, pois, o momento da sua desnaturação, como demonstra Marx. Tal relação ocorre

\footnotetext{
${ }^{16}$ Do original: "Bestimmungen der juristischen Person, eben des Individuums des Austauschs, entwickeln konnte und so das Recht (nach den Grundmestimmungen hin)".

17 Do original: "Jeder erscheint als Besitzer des Geldes dem anderen gegenüber, selbst das Geld, soweit der Prozeß des Austauschs betrachtet wird".
} 
porque "a condição prévia, o pressuposto não é, de modo algum, uma condição prévia para o indivíduo que decorre da vontade ou da natureza do mesmo indivíduo; mas é uma condição prévia, histórica, a estabelecer o indivíduo como já determinado pela sociedade" (Marx, 1983, p. 173, tradução nossa).$^{18}$

Nesta medida, a liberdade e a igualdade são postas de um modo geral pelo pensamento liberal, pois não são referidas há um tempo histórico particular e a indivíduos históricos particulares: o capitalista, o proletário, o camponês etc. Tais conceitos consubstanciam determinações abstrato-formais no sentido de negarem suas próprias formulações normativas; contudo, e como realidades formais, mágicas, é que se apresentam na realidade fenomênica. Convém sublinhar que, para Marx, estas aparências não são ilusões, mas fenômenos constitutivos do mundo social real. Existem, portanto, como diz Theodor Adorno, como aparências atuantes que norteiam efetivamente a prática de todos os agentes sociais envolvidos, e impõem-se 210 ante suas consciências como exterioridades imperativas, ou seja, como coisas, como se fossem existências autônomas, dotadas de vida própria e que se voltam contra seus criadores: os homens no interior de certas relações sociais e históricas.

Engendrado o fenômeno do estranhamento em relação ao produto de suas próprias criações, configura-se, então, a reificação de todas as relações sociais. Todas aparecem como naturais, sendo que a naturalização conforma um poderoso artefato ocultador das relações de domínio e de exploração existentes e necessárias ao funcionamento da sociedade burguesa. Afinal, semelhante realidade fenomênica produz e consome suas próprias aparências, e uma delas é a forma do contrato capitalista de trabalho. Como se sabe, a validade jurídica do contrato, aqui, supõe a existência de vontades autônomas, da igualdade e da liberdade dos agentes nele

18 Do original: “Daß also nicht nur die Voraussetzung keinesweges weder einem aus der Willen noch der unmitelbaren Natur des Individuums hervorgehende, sondern eine geschichtliche ist und das Individuum schon als durch die Gesellschaft betimmt setzt". 
envolvidos, capitalista e trabalhador. O contrato de trabalho, o pagamento pela prestação laboral, sua condição e sua duração são pactos firmados e que necessitam de uma regulação em favor da expansão do capital.

Neste momento, Marx empenha-se em desvendar o conteúdo das formas sociais que legitimam e legalizam aquilo que aparece na superfície da sociedade como dotadas de vontades autônomas, independentes do processo social que lhes dá origem. Assim é que Marx, no capítulo XVII do Livro I de O Capital"Transformação do Valor ou Preço da Força de Trabalho em Salário" (Verwandlung von Wert resp. Preis der Arbeitskraft in Arbeitslohn) -, demonstra como a identificação do salário com o "preço do trabalho" aparece e atua na sociedade como tal. Todavia, o que é o salário? É uma forma (ele a denomina de forma transmutada) que envolve misticamente, e igualmente, seus agentes principais, o capitalista e o proletário - o envoltório que extingue "todos os vestígios da divisão da jornada diária de trabalho em trabalho necessário e trabalho excedente em trabalho remunerado e não remunerado. Todo o trabalho aparece como trabalho remunerado" (Marx, 1969a, p. 562, tradução nossa) $;{ }^{19}$ enquanto na realidade não o é. Assim,

nesta forma de aparência, que torna invisível a relação visível e mostra exatamente o seu oposto, estão todas as relações jurídicas, seja do trabalhador, ou do capitalista, todas as mistificações do modo de produção capitalista, todas as suas ilusões de liberdade, todos os lapsos apologéticos do descanso vulgar da economia. (Marx, 1969a, p. 562, tradução nossa) ${ }^{20}$

\footnotetext{
19 Do original: "Die Form des Arbeitslohns löscht also jeder Spur der Teilung des Arbeitstags in notwendige Arbeit und Mehrarbeit in bezhlte und unbezahlte Arbeits aus. Alle Arbeit erscheint als bezahlte Arbeit".

20 Do original: "Auf dieser Erscheijungsform, die das sichtliche Verhältnis unsichtbar macht und grade sein Gegenteil zeigt, beruhn alle Rechtsvorstellungen des Arbeiters, wie des Kapitalisten, alle Mystifikationen der kapitalistischen Produktionsweise, alle ihrer Freiheit Illusionen, alle apologetische Flause der Vulgärökonomie”.
} 
As lutas incessantes dos trabalhadores para a redução da jornada de trabalho, normalmente reprimidas na maioria das vezes com violência, demonstram, por sua vez, seu verdadeiro caráter:

borra-se a nítida distinção entre público e o privado, a violência do Estado extravasa as antigas comportas e a luta social passa a contar com um novo contendor, os funcionários do Estado, nessa ambígua posição de representantes do todo e agentes do particular. (Gianotti, 1983, p. 299)

Desta feita, o que vem a ser a liberdade no que Marx identificou como: "mundo enfeitiçado, desumano e invertido, onde os manipansos, o senhor capital e a senhora terra, protagonistas sociais e ao mesmo tempo coisas, fazem suas assombrações"? Esta liberdade se encontra nos espa212 ços onde a reificação passa a ser uma verdadeira "religião da vida cotidiana” (Marx, 1969b, p. 838, tradução nossa), ${ }^{21}$ reduzidos a um mero cálculo economicista, "a proclamar em qualidade de dogma suas necessidades naturais de classe dominante" perante toda a sociedade (Marx, 1969b, p. 839 , tradução nossa).$^{22}$

Tal forma transmutada, tal categoria fenomênica, possui existência real, ativa. Mas o que ela oculta? Oculta o seu fundo, isto é, a relação social (capital) na qual ocorre a mais-valia, afinal, "na sociedade coisificada, nada sobrevive que por sua vez não tenha sido coisificado" (Adorno, 1998, p. 286, tradução nossa).$^{23}$ Toma-se como liberdade o que, de fato, é sujeição a um domínio muito potente,

\footnotetext{
${ }^{21}$ Do original: "Religion des Alltageslebens".

${ }^{22}$ Do original: "In dem sie die Naturnotwendigkeit und eiwige Berechtigung ihrer Einnahmequellen proklamiert und zu einen Dogma erhebt".

${ }^{23}$ Do original: Nichts hat innehalb der vedinglichten Gesellschaft eine Chance, zu überleben, was nicht seinerseits verdinglicht wäre.
} 
exatamente porque seu envoltório místico assume a forma de ações entre iguais e livres, que não são - as coisas e os fenômenos não são o que são.

As reconstituições do pensamento de Marx sobre este assunto constituem tarefa de equipes de pesquisadores em virtude da magnitude da sua investigação. De qualquer modo, é necessário assinalar que será nos Livros II e III d'O Capital, que Marx exporá sua análise da esfera da circulação do capital (não como coisa, mas como relação social, que, contudo, aparece também diante da consciência dos sujeitos como relação entre coisas).

Neste ponto, demonstrará como as formas de que o valor se revestirá se movimentam autonomamente, eclipsando todos os nexos causais das relações que lhes dão origem - as mediações desaparecem para dar lugar à dança das formas. Novamente, com o recurso a Adorno, os nexos de ofuscação se tornam cada vez mais fortes; as esferas da produção e da circulação, reciprocamente autônomas, possuem, no entanto, determinações específicas e engendram formas abstratas também próprias, isto é, fetiches específicos. E nesta realidade concreta acha-se a relação jurídica.

\section{Reificação e relações jurídicas}

Em carta a seu pai, de 10 de novembro de 1837, Marx escreve que a forma dos conceitos (die Begriffe Form) e o conteúdo (Inhalt) do Direito "podem e devem desenvolver-se separados um do outro" (Lottig, 1961, p. 3). ${ }^{24}$ Observa-se, então, a contradição que o ainda jovem Marx enxergava nas formas racionais do Direito que - mesmo jovem - descreverá pela primeira vez no seu conhecido texto a respeito dos "Debates sobre a lei do furto de madeira", aparecido

24 Do original: Das eine könne und müsse getrennt von dem aderen sich entwickeln. 
na Rheinische Zeitung no 298, de 25 de outubro de 1842, cuja autoria é atribuída a "um Renano" (von einem Rheinländer).

Marx separa neste texto as noções de Direito e de justiça, onde no mundo concreto um não quer dizer o outro, ${ }^{25}$ e onde um e outro existirão em suas formas independentes: os privilegiados realizam seus interesses por meio da legislação, e estes mesmos privilegiados não criam direitos, já que seus privilégios violam "o fundamento da igualdade de tratamento" (Lottig, 1961, p. 6, tradução nossa). ${ }^{26}$

A forma de questionamento de Marx sobre o Direito e sua reificação ganha em força argumentativa quando é desafiada a formação tradicional do Direito:

a natureza jurídica das coisas não pode, portanto, ser determinada pela lei; a lei é que deve ser determinada a partir da natureza jurídica das coisas. Se, no entanto, a lei chama de roubo de madeira aquilo que dificilmente seria um delito da madeira, então a lei mente e os pobres serão sacrificados por uma mentira legal. Há duas espécies de corrupções, afirma Montesquieu, uma quando os povos não observam as leis; a outra quando são corrompidos pelas

25 Embora esta observação integre a obra do jovem Marx, é perceptível a noção de direito natural que Marx mostrava neste primeiro escrito, durante o colapso de Weimar e que foi tão cara a pelo menos expressivo marxismo. Aqui se ressalta a compreensão de Ernst Fraenkel e sua insistência na recuperação do direito natural em Marx, como instrumento necessário ao enfrentamento contra o nazismo: "As reflexões de Weber deixaram aqui claramente uma impressão significativa em Ernst Fraenkel, que dedica grande parte da sua energia intelectual, durante as décadas de 1920 e 1930, a articular uma resposta à análise que Weber faz do direito natural e do socialismo. No processo, Fraenkel desenvolve uma síntese idiossincrática do direito natural e do marxismo que reconhece o inegável mérito intelectual da reivindicação de Weber - sem abandonar a própria referência de Fraenkel à social-democracia. [...] Fraenkel implica que o racionalismo e o intelectualismo modernos exigem o inevitável desaparecimento do direito natural e dos seus tesouros normativos" (Caldwell e Schuerman, 2000, p. 77-83, tradução nossa).

Do original: "den Grundsatz der Gleichbehandlung". 
leis; que é um mal incurável, porque contido no próprio remédio. (Marx, 1977a, p. 112, grifo do autor) ${ }^{27}$

Marx demonstra e percebe a natureza "mágica" do Direito para as relações econômicas e sociais, sem incorrer na ingenuidade de que tal confusão representaria a convicção da ilusão dos que mantiveram seus privilégios: estes possuem inteira consciência de seus atos, e da forma de criação do Direito para o fortalecimento cultural e intelectual de seus interesses.

A proposital e criativa divisão entre o Direito e justiça, ou a divisão entre os dizeres do normativismo e a situação concreta geral da sociedade, traduz uma divisão antecipada por Hegel, e que receberá também a crítica de Marx. Para Marx, separar a sociedade civil (bürgerliche Gesellschaft) do Estado político (politischer Staat) parece necessário (erscheint notwedig), a fim de também separar o cidadão, o cidadão do Estado (der Bürger, der Staatsbürger) de sua realidade empírica (empirischen Wriklichkeit) (Marx, 1977b, p. 281). E na mencionada realidade empírica encontram-se não somente as tensões da exploração e das desigualdades entre uns e outros, como também as raízes de tais explorações e desigualdades. Neste caminho, aliás, é que se encontra ainda a crítica do jovem Marx a Hegel, quando aponta a confusão de Hegel entre "o Estado como o existir por inteiro de um povo" com o Estado político como se de todos fosse (Marx, 1977b, p. 282, tradução nossa). ${ }^{28}$

\footnotetext{
27 Do original: "Die rechtliche Natur der Dinge kann sich daher nicht nach dem Gesetz, sondern das Gesetz muß sich nach der rechtlichen Natur der Dinge richten. Wenn das Gesetz aber eine Handlulng, die kaum ein Holzfrevel ist, einen Holzdiebstahl nennt, so lügt das Gesetz, und der Arme wird eine gesetzlichen Lüge geopfter. Il y a deux genres de corrpution, sagt Montesquieu, l'un lorsque le peuple n'observe point les lois; l'autre lorsqu'il est corrompu par le lois: mal incurable parce qu'il est dans le remède mêmè".

28 Do original: "Aber Hegel verwechselt hier den Staat als gazes Dasein eines Volkes mit dem politischen Staat”.
} 
O caminho da reificação em Marx passa pela complexa teia do Direito Privado. ${ }^{29} \mathrm{Na}$ Crítica da Filosofia do Direito de Hegel estão as análises a respeito da utilização do poder do Estado como consolidação do direito de propriedade e da imposição deste direito como o Direito do Estado possível. Para Marx, esta forma de idealização hegeliana corresponderia a uma base do Direito Privado que, por meio da propriedade sagrada, passa ser o Direito do Estado. A compreensão hegeliana seria, então, a de que as distinções no interior dos estamentos privados do Estado teriam significado apenas privado e jamais um significado político amplo. ${ }^{30} \mathrm{O}$ que Marx recusa é a assimilação de que o afastamento da política procura esconder-se na formulação normativa, isto é, no Direito. Nessa proposital recusa residiria inaceitável forma abstrata de compreensão da natureza do fenômeno jurídico.

Embora deva ser registrada a dificuldade de se encontrar uma Teoria do Direito em Marx, a busca por elementos mais 216 robustos para a compreensão do Direito pode se socorrer do pensamento marxista. Assim, a adequada indagação seria, portanto, o que pode o Direito ganhar com Marx e o marxismo?

Andrea Maihofer atualiza esta perspectiva de maneira singular. Como a grande maioria das pessoas, mesmo que conscientes das contradições históricas e estruturais do Direito nas sociedades, ainda mantém o mesmo modelo de Direito em suas mentes? "Por que as sociedades deixam-se regular deste modo?” (Maihofer, 1992, p. 51, tradução

\footnotetext{
29 A divisão entre Direito Público e Direito Privado tem origem na obra de Ulpiano (2010, p. 23): "Publicum ius est, quod ad statum rei Romanae spectat, privatum, quod ad singulorum utilitatem": Por direito público entende-se tudo o que diz respeito à coisa pública romana; privado, o que atende ao interesse de indivíduos: é a esta concepção estrita que Marx se refere, uma vez que esta era a ideia dominante sobre Direto Público e Privado no século XIX.

30 Do original: “daß die Unterscheidungen innerhalb des Privatstandes, die verschiedenen bürgerlichen Ständen, nun eine Privatebedeutung in bezug auf den Staat, keine politische Bedeutung haben".
} 
nossa) ${ }^{31}$ Não se trata somente de que seja esclarecida a "discrepância" (Diskrepanz) entre o Direito real e o positivado, mas sim, de que sejam devidamente esclarecidas tais discrepâncias do Direito como um todo, como um sistema social; "ou melhor dizendo: de todos os fenômenos com os quais as relações sociais de regras jurídicas têm a ver" (Maihofer, 1992, p. 51, tradução nossa). ${ }^{32}$ Procurar enxergar as múltiplas facetas da reificação no âmbito do Direito representa a busca por desvendar, nos fenômenos constitucionais e políticos, elementos até então "invisíveis" aos olhos dos que lidavam com a ciência jurídica. Após a reflexão marxiana, intelectuais e juristas passaram a dispor de uma metódica a mais para tratar sua ciência ante a um olhar interdisciplinar e mais enriquecedor de seu milenar fenômeno jurídico.

Vista sob esta forma, a reificação percebida por Marx torna possível que se compreenda um dos momentos mais significativos do constitucionalismo moderno, notadamente aquele que produziu constituições como a mexicana de 1917 e a de Weimar de 1919, isto é, o período entre as duas grandes guerras mundiais do século XX. Pela proximidade ontológica, a de Weimar deu-se numa sociedade do já avançado capitalismo, onde a luta política e social também incluía a considerável força política de organizados atores comunistas, liberais, socialdemocratas e socialistas, além de ter experimentado uma "democracia sem democratas", cujo colapso conduziu o mundo à barbárie de uma guerra sem precedente anticivilizatório, especialmente em relação a institutos jurídicos.

Weimar propôs um "compromisso mínimo" entre capital e trabalho, que pode ser resumido em seu "art. 151 [Fundamentos] A organização da vida econômica deve estar em conformidade com os princípios da justiça, com a

\footnotetext{
31 Do original: "Wie kommt es, daß die Menschen sich so etwas wie das Recht in den Kopfen setzen? Weshalb regeln sie ihre gesellschaftlichen Verhältnisse auf diese Weise?".

32 Do original: "oder genauer: alle Phänomene, die mit der rechtlichen Regelung gesellschaftlicher Verhältnisse zu tun haben".
} 
finalidade de corresponder a todos uma existência humana digna” (Schuster, 1985, p. 201, tradução nossa). ${ }^{33}$ Foi esta opção por uma sociedade menos desigual e por democracia nos moldes liberais que desencadeou a fúria do setor reacionário da Alemanha - nação egressa de uma derrota bélica e sem tradição democrática. Advinda de um processo revolucionário de novembro de 1918 para esta realidade, a Constituição de Weimar tentou dotar o país de ferramentas institucionais de superação de seus desafios, especialmente o de construção de uma sociedade econômica e politicamente democrática, além de tolerante. Nas palavras de Franz Neumann, estava-se diante de uma aposta para o futuro:

constituições escritas nos grandes momentos de viragem da história encarnam sempre decisões sobre as futuras estruturas da sociedade. Além disso, uma constituição é mais do que o seu texto jurídico; é também um mito que exige lealdade de um sistema eternamente válido. (Neumann, 2009, p. 8, tradução nossa)

Os socialdemocratas de Weimar tiveram a habilidade de realizar a transição de monarquia reacionária para uma tentativa democrática, ao mesmo tempo em que foram capazes de construir governos em momentos tormentosos das esferas econômica e política da Europa entreguerras. Os mesmos socialdemocratas não estavam preparados para a força de um inimigo tão poderoso, o nacional socialismo, que destruiu as precárias bases de uma democracia ainda na sua infância. Para esta destruição, a colaboração de juristas e do Poder Judiciário desempenhou relevante papel:

\footnotetext{
33 Do original: Art. 151 [Grundsätze] Die Ordnung des Wirtschaftslebens muß den Grundsätzen der Gerechtigkeit mit dem Ziele der Gewährleistung eines menschenwürdigen Daseins für alle entsprechen.
} 
no centro da contrarrevolução estava o poder judiciário. Ao contrário dos atos administrativos, que se baseiam em considerações de conveniência e oportunidade, a decisão judicial repousa na lei, ou seja, no certo e no errado, e eles sempre gozam da luz da ribalta da publicidade. O direito é talvez a mais perniciosa das armas nas lutas políticas, precisamente por causa da auréola que envolve os conceitos de direito e justiça. (Neumann, 2009, p. 20, tradução nossa)

Mais que o Poder Judiciário, o trabalhar de conceitos e instituições jurídicas para sua adaptação à institucionalidade nazista, e consequente ruptura com a "república marxista judaica” de Weimar (Hürter, 2016, p. 13), comprova a necessidade da observação do fenômeno da reificação com novo significado, porém com o objetivo de manter formas de dominação de classes e estamentos sociais, uns sobre os outros. Assim, a radicalidade nazista traz a novidade na fixação do conceito de amigo-inimigo, a fim de que o inimigo não seja simplesmente dominado e neutralizado, mas eliminado em sua existência pessoal, cultural, econômica e política.

O Direito como um todo - e não somente o Direito Público, o Privado ou o tradicional Direito do Estado Staatsrecht alemão - passará a ser compreendido no sentido de, ao mesmo tempo, ser submetido e consolidar a moral nazista. A desnecessidade da lei frente à nova moral elaborada pelo nazismo fez com que conceitos de pureza racional, superioridade cultural, científica e econômica oferecessem racionalidade para decisões administrativas e judiciais. A transição para o nacional socialismo teve, portanto, na "moralização ideológica do Direito" (ideologische Moralisierung des Rechts) sua especial função, na qual à forma de Estado da República de Weimar

faltaria uma relação interna com o povo alemão, a qual, do ponto de vista teórico do Direito, esgota-se num formalismo positivista sem substância. Como escreve 
Koellreutter: a derrubada de novembro de 1918 trouxe para a Alemanha uma vitória extraordinária da democracia formal e do positivismo jurídico. (Pauer-Studer, 2014, p. 13, tradução nossa) ${ }^{34}$

A crítica dos juristas contra Weimar vem, também, de um dos mais proeminentes juristas, Ernst Forsthoff, para quem esta constituição nada mais seria do que "a tentativa de um Estado sem substância (den Versuch zum Staat ohne Substanz)" (Forsthoff, 1933, p. 20). Como Weimar não escolheu sua substância - que poderia ser a "monarquia segundo a graça de deus, o povo, o líder, um mito" (die Monarchie von Gottes Gnaden, das Volk, der Fürher, ein Mythos sein) (Forsthoff, 1933, p. 20) -, seu vazio estaria somente no Direito positivado.

Não é necessário, portanto, muito esforço para perceber que a batalha intelectual e política a ser travada dar-se-ia ainda no interior da burocracia do Estado nazista, o qual se 220 consolidava, e tinha em Hans Kelsen e na sua Teoria Pura do Direito os grandes adversários a serem eliminados. A conquista da legalidade procurou deslocar para o território da objetividade a aplicação da constituição e das leis, na qual poderiam ganhar setores populares mais abrangentes, uma vez que juízes estariam vinculados à legalidade, e não aos alegados valores morais tradicionais da sociedade. A clássica separação entre Direito e moral do positivismo consistiu no principal alvo do nazismo, de forma a confundir a interpretação judicial com a moral, e, sob esta forma, impossibilitar que os próprios juristas e juízes identificassem as devidas diferenças quando se tratava de autoritarismo, ou quando se estava diante da "estatalidade" do Direito (Rechtsstaatlichkeit).

\footnotetext{
34 Do original: "die Weimarer Republik als eine Staatsform, der die innere Beziehung zum deutschen Volk fehle und die sich rechtstheoretisch im positivistischen und substanzlosen Formalismus erschöpfe. Wie Koellreutter schreibt: Das Novemberumsturz des Jahres 1918 brachte in Deutschland eine äußerlichen Sieg der formalen Demokratie und des Rechtspositivismus".
} 
Esta reificação do Direito pela moral não foi, claro, enfrentada por Marx. Porém, seu conceito de reificação de relações sociais dá pistas de como a complexa operacionalização do nacional socialismo foi bem-sucedida na tarefa de reificar sua visão de mundo e de sociedade na direção de construir uma deformada compreensão política sobre moral e Direito, que correspondia ao interesse substancial da nova forma de organização política.

Nos dias que se seguiram durante o domínio do nacional socialismo, o Direito passou a ter a tarefa de reificação do sistema de valores do nazismo, deixando, com isso, a prova histórica de que a normatividade sozinha não dá conta da natureza explicativa dos fenômenos constitucionais; e de que seria necessário ao sistema de valores morais, além do Direito escrito, positivado, juntar a ação concreta política da burocracia judiciária.

\section{Reificação como estrutura da consciência política}

A amplitude fenomênica da reificação das relações sociais faz com que formas adquiram roupagens cada vez mais refinadas, dotadas de forças ocultadoras mais potentes, e, o mais importante, mais autônomas e que compareçam na vida cotidiana dos indivíduos como dádivas, acidentes da natureza. A forma juros do capital-dinheiro talvez se configure como a maneira mais acabada de fetiche, de coisa portadora de movimento, de ritmo, de luz própria. Na mesma medida em que se desenvolve e se torna mais complexo o próprio capitalismo e, sobretudo, na relação da sociedade civil com o Estado, mais ficam invisíveis os nexos causais internos às relações sociais. $\mathrm{O}$ dinheiro, na forma de movimento do valor, aparece dotado de potência própria, transferindo-a, então como tal, às suas personificações sociais, no caso, os proprietários do dinheiro - como lembrava Marx, o dinheiro tem o poder de tudo vincular e de tudo desvincular. A complexidade social e as diversidades das relações tornam ainda mais difícil estabelecer as mediações capazes 
de recompor, ao nível da reflexão, a unidade do processo real de produção e do processo de circulação do capital.

Capitalismo avançado, agora, financeirizado internacionalmente, equivale, de um lado, à forte centralização de capitais e, de outro, à correspondente transfiguração do Estado que, então, assume mais o caráter de representante do "interesse geral", sem que o seja. Este se consubstancia na busca da riqueza abstrata do dinheiro que gera mais dinheiro, tornando esta sua prática social e política dominante.

Nesta condição, produz incessantemente o discurso da suposta racionalidade em apresentar-se como sujeito fundamental das práticas virtuosas da austeridade, do cálculo fiscalista que, também, materializam-se por meio de instrumentos normativos. Entre nós, a brasileira Lei Complementar n⿳0 101 , de 04 de maio de 2000 - ou "lei de responsabilidade fiscal" - responde pelo melhor exemplo deste pretenso discurso da supra racionalidade; a sociedade haverá de ser controlada nos 222 seus impulsos desejantes da vida boa. Trata-se de se apresentar como responsável pelo controle dos resultados da labuta social, de se autoproclamar como a única agência com capacidade racional e, para tanto, seus porta-vozes não hesitam em sepultar, no porão da história, todas as conquistas civilizatórias.

As heranças da civilização e das lutas sociais comparecem nas práticas discursivas dos Estados como testemunhas vivas das irracionalidades da sociedade, sobretudo as conquistadas pelas lutas democráticas pela vida boa - Welfare State soa como delírio, como irresponsabilidade e loucura coletiva. O mundo das coisas, dos fantasmas, invade todos os recantos da vida social, e a reificação aparece como iniludível racionalidade que se encarna nas práticas de austeridade fiscal. Pagar juros da dívida pública encerra um dos mistérios destas novas formas de apresentação como representantes do interesse universal - formas arcaicas de religiosidade e de práticas sociais discriminatórias ganham status de racionalidade máxima, uma vez que todas se fundem no mito do 
Estado mínimo. Na verdade, os indivíduos voltaram a ser desnudados, estão novamente nus, tal como chegaram à tão coisificada modernidade, desnudados que foram nos séculos da chamada acumulação primitiva. Chegaram à saudada modernidade totalmente nus e, destituídos de seus antigos direitos, passaram a transitar no mundo como seres disponíveis a qualquer uso de suas carnes e músculos.

Desta feita, objetivou-se o domínio do mundo das coisas sobre os destinos da humanidade. Isto confirma o grande temor de Marx, qual seja: o domínio das forças cegas do mercado, das suas potências mais destrutivas, aquelas que não se detêm diante de nada: da morte, da guerra e do terror.

Diante de tudo isso, o que nos resta? Ou melhor, o que vem a ser a liberdade neste mundo que Marx (1969b, p. 838) detectou como "o mundo encantado, invertido e posto de cabeça para baixo, onde Monsieur le Capital e Madame la Terre assombram como fantasmas, ora como personagens sociais e ao mesmo tempo como meras coisas?".

A liberdade aqui permanece a inscrever-se em possível histórico que persegue, necessariamente, certos passos determinados. Que determinações são estas? São aquelas advindas do próprio desenvolvimento do capitalismo e das necessidades, enfim, da luta social. Efetivamente, trata-se da emancipação do trabalho e de toda a ideologia que o acompanha (ética calvinista etc.), o que remete, imediatamente, à questão da relação entre reino da liberdade e reino da necessidade. Onde começa, então, o reino da liberdade? Ou seja, a liberdade, para triunfar, supõe a superação do reino do imprescindível - a produção e a reprodução da vida; supõe, portanto, um desenvolvimento das forças produtivas capazes de satisfazer as sempre novas necessidades humanas, como também ampliá-las, alargando, ao mesmo tempo, os modos de satisfazê-las.

Esta dialética, pois, entre a liberdade e a necessidade está fundada na história de homens reais e concretos. O início desta longa e penosa travessia pressupõe a luta política, a 
qual se inicia, antes de tudo, ao que parece, com a conquista de direitos sociais pelos trabalhadores: efetivamente, a começar pela condição fundamental desse desenvolvimento humano que é a redução da jornada de trabalho. E a esfera da política, para Marx, é o momento da universalidade, ou seja, é a passagem e a superação do particular. Pode-se apreender isto quando ele procede à distinção entre o movimento social dos trabalhadores como sendo, inicialmente, particularista, parcial, episódico e descontínuo (do ludismo às primeiras coligações de trabalhadores por lutas salariais) até sua configuração em movimento político - este último configurando o momento das associações permanentes, o partido político, por exemplo.

Neste momento, colocam-se questões político-institucionais que transcendem o movimento operário tomado de per si: referimo-nos ao sufrágio universal masculino. O cartismo inglês é referido por Marx como o momento em que uma perspectiva imediatista, particularista, é superada por uma concepção mais universalizante da ação política. O momento da política e da formação de normas e leis que protejam os trabalhadores por meio das lutas e alianças, e espertezas e truques destas. $\mathrm{Ou}$ seja, tais momentos podem redefinir o princípio e a prática da cidadania (Marx, 1990). Deste ponto em diante, a cidadania alarga-se cada vez mais e redefine seu próprio sentido.

Por isso, nos dias que correm, em países em que sequer os direitos civis, políticos e sociais foram conquistados e, mais importante, assegurados e praticados efetivamente, a construção da esfera institucional liberal-democrática constitui um imperativo histórico. Todavia, nesta altura da história mundial do capitalismo não podemos desconhecer o risco de reificação das instituições, pois elas podem nos mergulhar perigosamente no mundo obscuro e invertido das ilusões formais; podem nos fazer emergir em novas formas de intransparência e reificação da vida social. 
Assim, informados pela experiência da história sobre os limites e alcances do Estado de Direito na sociedade moderna, parece-nos, entretanto, que pelo menos para nós, a instituição desse Estado se faz imperiosamente necessária. Somente isso poderá potencializar a criação de uma cultura política democrática indispensável à luta pela construção do reino da liberdade.

\section{Breve conclusão}

As considerações feitas anteriormente sobre as estruturas reificadas de consciência servem porque nos conduzem à retomada sociológica da crítica social, mais uma vez como crítica radical da ideologia, ou seja, das formas sociais que reificam a consciência, que modelam as estruturas profundas dos nossos sentimentos, da nossa percepção do mundo. As ideologias são ideias, conformam sistemas de convicções e sistemas de crenças; transformam-se, assim, em hábitos de pensar e agir dos homens e têm consequências práticas na vida social. Tais sistemas operam empiricamente, constituem práticas sociais, institucionais e simbólicas como na forma também analisada por Rahel Jaeggi (2016b).

Os homens atuam no mundo pela ideologia - no sentido de Marx, são movidos em suas ações por este amplo sistema de encantamento. Como vimos, as formas ideológicas ocultam as relações de domínio e, no entanto, penetram de forma invertida como na conhecida e famosa imagem feita pelo autor da câmera escura que inverte a forma dos objetos por ela refletidos. Porém, a inversão penetra fundamente na mente dos indivíduos, e assim se transmuta em violência material.

Crítica radical da ideologia é simultaneamente crítica do domínio e da exploração. Semelhante crítica deve decifrar os mecanismos profundos da dominação, iluminá-los na escuridão das luzes do progresso e constituir-se no grande desafio do pensamento que se quer pensamento. Criticar a reificação da hipnose jurídica a partir da formação de conceitos do Direito, de formas distanciadas da realidade, será o elemento 
da possibilidade de compreensão do funcionamento do Direito para além das aparências que esta mesma ciência jurídica constituída procura esconder a fim de manter separada da realidade a potentia humana de sua liberação - material e imaterial - dos limites da alienação, que somente pode ser enfrentada pelo "fazer de um que é o fazer do outro" (Jaeggi, 2016a, p. 298, tradução nossa).$^{35}$ Esta atualidade da reflexão marxista comprova-se para além do universo artístico, na reflexão teórica. Nancy Fraser, em discussão recente com Rahel Jaeggi, enxerga a luta de fronteiras (boundary struggles) não como uma substituição da luta de classes de Marx (Fraser; Jaeggi, 2018, p. 168, tradução nossa), mas como um conceito que pertence:

no mesmo marco conceitual da visão ampliada da luta de classes que acabo de delinear, inclui-se também lutas sobre o trabalho não remunerado e expropriado, incluindo a reprodução social, e sobre as condições naturais e políticas que o sustentam.

Neste sentido, podemos retomar proficuamente o legado de Marx e assim, de fato, render-lhe a homenagem que lhe devemos em seu aniversário de 200 anos. Como certa vez lhe sentenciou Marshall Berman: Marx ainda continuará dançando na Broadway, quando todos nós estivermos mortos.

\section{Martonio Mont'Alverne Barreto Lima}

doutor e pós-doutor em Direito pela Universidade de Frankfurt am Main/Alemanha, atualmente é professor titular da Universidade de Fortaleza e procurador do município de Fortaleza.

\section{Walquíria Gertrudes Domingues Leão Rego}

professora titular aposentada do Instituto de Filosofia e Ciência Humanas da Universidade Estadual de Campinas

35 Do original: Das Tun des Einen ist das Tun des Anderen. 
(Unicamp), livre-docente pela Unicamp, tem experiência na área de Sociologia, trabalha atualmente com pesquisa sobre o programa Bolsa Família, resultante na obra Vozes do Bolsa Família, da Universidade Estadual Paulista (Unesp), de 2013.

\section{Bibliografia}

ADORNO, Theodor Wiesengrund. 1998. Einleitung zum

"Positivismusstreit in der deutschen Soziologie". In: ADORNO,

Theodor Wiesengrund. Gesammelte Schriften. Darmstadt:

Wissenschaftliche Buchgesellschaft, pp. 280-353.

BODEI, Remo. 2004. Destini personali: l'età della colonizzazione delle coscienze.

Milano: Feltrinelli.

BOTTOMORE, Tom. 1983. Dicionário do Pensamento Marxista. Rio de

Janeiro: Jorge Zahar.

BUCKHARDT, Jacob Christoph. 1990. A cultura do Renascimento na Itália: um ensaio. São Paulo: Companhia das Letras.

CALDWELL, Peter; SCHUERMAN, Wiliam E. 2000. From liberal democracy to fascism. Boston: Humanities Press.

CAMÕES, Luiz Vaz de. 2014. Os Lusíadas. Porto: Porto Editora.

COHEN, Gerald A. 2013. A teoria da história de Karl Marx: uma defesa.

Campinas: Editora Unicamp.

ESPINOZA, Baruch de. 2003. Tratado Teológico-Político. São Paulo:

Martins Fontes.

FORSTHOFF, Ernst. 1933. Der totale Staat. Hamburg: Hanseatische

Verlagsanstalt.

FRASER, Nancy; JAEGGI, Rahel. 2018. Capitalism: a conversation in critical theory. Cambridge: Polity Press.

GIANOTTI, José Arthur. 1983. Trabalho e reflexão. São Paulo: Brasiliense.

HONNETH, Axel. 2007. Reificación: un estudio en la teoria del reconocimiento.

Buenos Ayres: Katz.

HORKHEIMER, Max. 1976. Eclipse da Razão. Rio de Janeiro: Labor do Brasil.

HORKHEIMER, Max; ADORNO, Theodor Wiesengrund. 1997. Dialetik der Aufklärung - Philosophische Fragmente. In: ADORNO, Theodor Wiesengrund. Adorno Gesammelte Schriften. Darmstadt: Wissenschaftliche Buchgesellschaft, pp. 7-335.

HÜRTER, Joahnnes (ed.). 2016. Notizen aus dem Vernichtungskrieg - Die Ostfront 1941/42 in den Aufzeichnungen des Generals Heinrici. Darmstad:

Wissenschaftliche Buchgesellschaft. 
JAEGGI, Rahel. 2016a. Entfremdung: Zur Aktualität eines sozialphilosophischen Problems. Frankfurt am Main: Surhkamp.

JAEGGI, Rahel. 2016b. Forme di vita e capitalismo. Torino: Rosenberg \& Sellier. JAEGGI, Rahel; LOICK, Daniel; MARX, Nach. 2017. Philosophie, Kritik, Praxis. Frankfurt at Main: Suhrkamp.

LOTTIG, Hans. 1961. Marx und das Recht: Untersuchungen zu den Schriften von Karl Marx. Hamburg: Forschungsstelle für Völkerrecht und ausländisches öffentliches Recht der Universität Hamburg.

LUKÁCS, Georg. 2003. História e consciência de classe: estudos sobre a dialética marxista. São Paulo: Martins Fontes.

MAIHOFER, Andrea. 1992. Das Rech bei Marx - Zur dialektischen Struktur von Gerechtigkeit, Menschenrecht und Recht. Baden-Baden: Nomos Verlags-gesellschaft.

MARX, Karl. 1969a. Das Kapital: Erster Band. Berlin: Dietz.

MARX, Karl. 1969b. Das Kapital: Dritter Band. Berlin: Dietz.

MARX, Karl. 1977a. Debatten über das Holzdiebstahlgesetz. Berlin: Dietz.

MARX, Karl. 1977b. Zur Kritik der Hegelschen Rechtsphilosophie. Berlin: Dietz.

MARX, Karl. 1983. Grundrisse der Kritik der politischen Ökonomie. MEW Bd. 42. Berlin: Dietz.

MARX, Karl. 1990. Das Elend der Philosophie: Antwort auf Proudhon "Philosopgie des Elends". Berlin: Dietz.

MÜLLER, Friedrich; CHRISTENSEN, Ralph. 2002. Juristische Metodik: Grundlagen Öffentliches Recht. Berlin: Duncker \& Humblot.

NEUMANN, Franz. 2009. Behemot - The Structure and Practice of National Socialism, 1933-1944. Chicago: Ivan R. Dee.

PAUER-STUDER, Herlinde. 2014. Jenseits vom Chaos und von Interessenkonflikten. Aspekte der Rechtsentwicklung im NS-System der 1930er Jahre. In: KONITZER, Werner; FOLJANTY, Lena (eds.). Moralisierung des Rechts. Kontinuitäten und Diskontinuitäten nationalsozialistischer Normativität. Frankfurt am Main: Campus. pp. 11-42. PLATÃO. Sofista: os pensadores. 1991. São Paulo: Nova Cultural. SCHUSTER, Rudolf (ed.). 1985. Deutsche Vergassungen: Die Verfassung des Deutschen Reiches (Weimarer Verfassung): August 1919. München: Goldmann. SHAW, William H. 1978. Marx's Theory of History. Stanford: Stanford University Press.

SPINOZA, Baruch de. 2008. Tractatus Theologico-Politicus: Opera.

Darmstadt: Wissenschaftliche Buchgesellschaft.

STRAUSS, Leo. 2014. Derecho natural e historia. Buenos Aires: Prometeo Libros. ULPIANO, Eneu Domício. 2010. Corpus iuris civilis digesto: livro I. Brasília, DF: Tribunal Regional Federal da 1ª Região. 


\section{ATUALIDADE DA REIFICAÇÃO DE MARX COMO INSTRUMENTO DA ANÁLISE DE RELAÇÕES JURÍDICAS E SOCIAIS}

\section{MARTONIO MONT'ALVERNE BARRETO LIMA; WALQUÍRIA GERTRUDES DOMINGUES LEÃO REGO}

Resumo: Este artigo procura investigar a reflexão de Karl Marx sobre a reificação das relações sociais no desenvolvimento econômico e político do sistema capitalista, a partir da noção de reificação - Verdinglichung - estabelecida no Livro III de $O$ Capital. Trata-se de uma tentativa de reinserir o assunto no atual debate sociológico-jurídico, que se desenvolve em muitos lugares do mundo. Consideramos o conceito de reificação como um conceito-diagnóstico, ou pelo menos um elemento indispensável de diagnose de uma época histórica. Isto se deve, na verdade, ao fato de tal debate tratar de um fenômeno ligado às formas de consciência e dos conjuntos de práticas sociais inspirados nela, e que podem singularizar um determinado tempo histórico. Semelhante campo temático foi abandonado por anos, ao menos desde os anos de 1980, pelas ciências sociais e jurídicas. Contudo, deve ser dito que tal temática foi central nos debates na Alemanha, na Áustria e na América Latina nas décadas de 1920 e 1930. Assim, o texto do artigo parte desta necessidade histórica para propor uma atualização do conceito de reificação, o qual pode ser atualizado para os tempos modernos, o que confere ao Direito uma preciosa ferramenta ontológica de explicação de suas formas fenomênicas da modernidade.

Palavras-chave: Karl Marx; Direito; Verdinglichung; Reificação; Relações Sociais; Relações Jurídicas. 


\section{HOW CURRENT IS THE REIFICATION OF MARX AS AN INSTRUMENT TO ANALYZE LEGAL AND SOCIAL RELATIONS}

Abstract: This article investigates Karl Marx' reflection on the reification of social relations in the economic and political development of the capitalist system according to the notion of reification (Verdinglichung) established in Book III of The Capital. This is an attempt to resurge the subject in the current sociological-legal debate which is being developed in many places of the world. We consider the concept of reification as a conceptdiagnosis, or at least an indispensable element for the diagnosis of a historical epoch. This is due, in fact, to the fact that such a debate deals with a phenomenon related to the forms of consciousness and the sets of social practices inspired by it, which can make unique a certain historical time. Such a thematic field has been abandoned for years, at least since the 1980s, by the social and legal sciences. It must be said, however, that this topic was central to the German, Austrian and Latin American debate in the 1920s and 1930s. Thus, this paper starts from this historical need to propose an update of the concept of reification, which can be updated for modern times, providing Law a precious ontological tool to explain its phenomenal forms of modernity.

Keywords: Karl Marx; Law; Verdinglichung; Reification; Social Relations; Legal Relations.

Recebido: 16/08/2019 Aprovado: 27/03/2020 